\title{
EFEITO RESIDUAL DOS HERBICIDAS IMAZAQUIN E IMAZETHAPYR, APLICADOS NA SOJA, SOBRE O MILHO SAFRINHA ${ }^{1}$
}

\author{
ADOLFO V. ULBRICH ${ }^{2}$, BENEDITO N. RODRIGUES ${ }^{3}$ e JOÃO DE LIMA ${ }^{4}$
}

\section{RESUMO}

Com o objetivo de se avaliar os efeitos da persistência dos herbicidas imazaquin e imazethapyr na cultura do milho safrinha em sucessão à da soja, tratada com estes produtos, foi instalado um ensaio na Fazenda Escola da Universidade Estadual de Londrina, solo argiloso (75\% de argila), na safra agrícola 1995/96. O delineamento experimental adotado foi o de blocos ao acaso, com parcelas subdivididas em faixas. Os tratamentos principais foram constituídos pelos herbicidas: 1.Testemunha; 2.Imazaquin PPI -120 g.i.a./ha; 3.Imazaquin PPI - 240 g.i.a./ha; 4.Imazethapyr PRE - 80 g.i.a./ha e 5.Imazethapyr PRE - 160 g.i.a./ha. Os tratamentos secundários foram constituídos pelas épocas de semeadura do milho: 0 (zero), 30, 60, 90, 120 e 150 dias após a aplicação - DAA. As avaliações, tanto de fitotoxicidade visual como de biomassa seca das plantas e produtividade do milho, revelaram uma maior sensibilidade da cultura ao imazaquin do que ao imazethapyr, embora a quantidade ( $\mathrm{ppb}$ ) de imazethapyr encontrada nas análises cromatográficas das amostras de solo (HPLC) tenha sido maior que a de imazaquin. Nos primeiros plantios, o imazaquin causou dano praticamente total às plantas, enquanto o imazethapyr proporcionou uma injúria de $30-40 \%$ na dose normal (80 g.i.a./ha). Nos plantios após 120 DAA esses sintomas foram diminuindo gradativamente até desaparecerem. A curva de regressão dos dados de colheita revelou intervalos de 87 e 112 dias para imazethapyr e imazaquin, respectivamente, para que não mais houvesse diminuição na produtividade do milho semeado após a aplicação da dose normal destes produtos. Correlacionando-se os parâmetros avaliados, observou-se que, mesmo havendo fitotoxicidade no início do desenvolvimento das plantas de milho, essas se recuperaram, tendo produtividade normal após os referidos intervalos. Dos parâmetros avaliados no bioensaio com pepino (Cucumis sativus), a biomassa seca das plantas confirmou a maior sensibilidade do pepino em relação ao milho, sendo prejudicada pela ação residual dos herbicidas no solo até o intervalo mínimo de 127 e 135 DAA para imazethapyr 80 g.i.a./ha e imazaquin - 120 g.i.a./ha, respectivamente.

Palavras chaves: resíduo, cromatografia, bioensaio, imidazolinonas, fitotoxicidade.

\section{ABSTRACT}

\section{Carryover effects of Imazaquin and Imazethapyr on corn planted right after soybean}

The effects of imazaquin and imazethapyr on corn (safrinha) planted right after the soybean were studied on a clay soil ( $75 \%$ clay) in Londrina,
State of Paraná, Brazil, during the season 1995/96. Imazaquin was applied to soybean at 120 and 240 gai/ha PPI and imazethapyr was applied at 80 and

\footnotetext{
${ }^{1}$ Recebido para publicação em 22/05/98 e na forma revisada em 14/08/98.

2 Aluno de pós-graduação, nível mestrado, UEL. C.P. 2251, CEP 86100-000, Londrina/PR.

${ }^{3}$ Pesquisador Científico, PhD, Instituto Agronômico do Paraná e orientador do Curso de Mestrado da UEL/EMBRAPA/IAPAR. C.P. 481, CEP 86001-970, Londrina/PR.

${ }^{4}$ Eng $^{\circ}$ Químico, M.Sc., Laboratório de Ecofisiologia, Instituto Agronômico do Paraná. C.P. 481, CEP 86001-970, Londrina/PR.
} 
160 gai/ha at pre emergence. Corn was planted every 30 days from application till harvest (150 DAA). The corn crop was much more sensitive to imazaquin than to imazethapyr although the residue of imazethapyr found in the soil samples (HPLC) was higher than imazaquin till 90 DAA. In the first month after application the residual of imazaquin caused high crop injury to corn while imazethapyr caused 30-40\% injury at normal rate. Yield results showed no damage after 87 days for imazethapyr

\section{INTRODUÇÃO}

Devido à sua grande importância econômica e alimentícia, a cultura da soja tornou-se uma das mais expressivas em nosso país. Por ser um produto destinado à exportação, gera riquezas à economia e traz divisas ao Brasil, constituindo-se numa grande opção agrícola. O país ocupa, na atualidade, o segundo lugar em termos de produção mundial deste grão e é o primeiro exportador de farelo de soja (IBGE, 1996).

O uso de herbicidas para o controle de plantas daninhas é hoje o método mais eficiente e, especialmente em grandes áreas, o mais econômico. Na safra 95/96, o Paraná teve uma área plantada de soja de 2.100 .000 ha e, aproximadamente, $55 \%$ desta área foi tratada com os herbicidas imazaquin (Scepter) e imazethapyr (Pivot). (Cyanamid, 1996). ${ }^{4}$

Os dois produtos pertencem ao grupo químico das imidazolinonas e estão registrados no Brasil para uso exclusivo na cultura da soja, sendo o primeiro utilizado em pré-plantio e incorporado (PPI) e em pré-emergência da cultura e o segundo, em pós-emergência da mesma (Rodrigues \& Almeida, 1995). Segundo Shaner et al. (1984), ambos os produtos possuem características de persistência no solo, o que para a cultura da soja é muito favorável, pois proporciona o controle residual das plantas daninhas durante o seu ciclo. Mas esta característica também constitui num risco para as culturas sucessivas à soja.

\footnotetext{
${ }^{4}$ Relatório interno da empresa - Cyanamid Química do Brasil Ltda - Rio de Janeiro, 1996
}

(80 gai/ha) and after 112 days for imazaquin (120 g.i.a./ha) application. After these periods, the corn plants showed somewhat early crop injury. In a bioassay test cucumber (Cucumis sativus) showed higher sensitivity compared to corn. The dry weight data showed no difference after 127 days for imazethapyr application and after 135 days for imazaquin application.

Key words: herbicide persistence, herbicide carryover, imidazolinone, phytotoxicity.

Muito se tem pesquisado com imazaquin e imazethapyr, visando esclarecer os mecanismos que implicam na persistência e mobilidade destes produtos no solo, com o principal objetivo de se determinar o potencial de injúria às culturas subsequentes. Geralmente, a maioria dos herbicidas com atividade residual no solo, é muito afetado pelo $\mathrm{pH}$, teores de argila e matéria orgânica do solo. Quando as condições de adsorção do herbicida são favorecidas, ocorre uma queda na sua atividade e mobilidade. Vários estudos têm mostrado que a adsorção do imazaquin aumenta com o decréscimo do pH (Goetz et al. ,1986; Loux et al., 1989). Renner et al. (1988) observou ainda que a adsorção do imazethapyr é maior que a do imazaquin nos diferentes pHs estudados. Cantwell et al. (1989) afirma que o grau de adsorção do herbicida no solo é um fator que influencia a taxa de degradação, devido a não disponibilidade das moléculas adsorvidas aos microorganismos responsáveis pela degradação. Como consequiência, geralmente os herbicidas persistem mais em solos com maiores teores de argila e matéria orgânica e baixo pH de solo (Milanova \& Grigorov, 1996). Como exemplo, Marsh \& Lloyd (1996) citam que a dissipação do imazaquin no solo foi rápida durante as primeiras 12 semanas após a aplicação onde o $\mathrm{pH}$ do solo era superior a 5,5 mas, significativamente mais lento em $\mathrm{pH}$ menores.

Os fatores climáticos também são de grande influência na persistência dos produtos. Flint \&Witt (1997) concluíram que a umidade ideal para a degradação destes herbicidas é de $75 \%$ da capacidade de campo. No mesmo trabalho eles relatam que a persistência de ambos os produtos foi 
duas vezes maior a $15^{\circ} \mathrm{C}$, quando comparada a $30^{\circ} \mathrm{C}$; e ainda comentam que essa característica é típica de produtos degradados por microorganismos. Johnson \& Talbert (1996) afirmam que a degradação principal do imazaquin e do imazethapyr é por via microbiana.

No que diz respeito à forma, a aplicação em pré-plantio e incorporado apresenta risco de injúria à cultura sucessiva maior que a de préemergência. Isto pode ser explicado pelo fato do imazaquin sofrer foto-decomposição, quando permanece na superfície do solo. Neste caso, a aplicação em PPI protege o herbicida da ação dos raios ultra-violeta e infra-vermelho, diminuindo sua decomposição e aumentando sua persistência (Loux \& Reese, 1992 e Curran et al., 1992).

A cultura do milho tem sido bastante utilizada como cultura em rotação à soja para análise do potencial de injúria. Loux et al. (1989) verificaram que o milho é mais sensível ao imazaquin que ao imazethapyr. Bashan \& Lavy (1987) mostraram que esta sensibilidade pode ser observada em concentrações baixíssimas (1 ppb) de imazaquin no solo, o que pode causar diferenças entre as análises feitas em laboratório e os testes em campo, uma vez que os resíduos encontrados podem não estar disponíveis às plantas. Moyer \& Esau (1996) observaram injúrias e queda na produção de linho, milho, mostarda, girassol e trigo semeados em até um ano após a aplicação de 200 g.i.a./ha de imazethapyr, na canola semeada em até dois anos após e em batata e beterraba açucareira semeadas em até três anos após a mesma aplicação.

Apesar da literatura oferecer vários trabalhos nesta área, quase todos eles foram realizados nos Estados Unidos e na Europa, em condições bem diferentes das condições tropicais brasileiras, o que modifica em muito o comportamento dos produtos no solo e a resposta da cultura do milho, quando em sucessão à soja.

Dentro dessa linha de pesquisa, delineouse o presente trabalho, cujo objetivo é avaliar o efeito residual dos herbicidas imazaquin $\mathrm{e}$ imazethapyr, aplicados na cultura da soja, sobre o milho safrinha nas condições do norte do Paraná.

\section{MATERIAL E MÉTODOS}

\section{Experimento de Campo}

O experimento de campo foi instalado na Fazenda Escola da Universidade Estadual de Londrina, localizada no município de Londrina$\mathrm{PR}$, situada a $23^{\circ}$ e $30^{\prime}$ de latitude $\mathrm{S}$ e $51^{\circ}$ e $11^{\prime}$ de longitude $\mathrm{W}$, com altitude de $560 \mathrm{~m}$, com clima tipo Cfa, segundo a classificação de Kopen, com solo descrito como terra roxa estruturada de textura argilosa $(75 \%$ de argila, $14 \%$ de silte e $11 \%$ de areia) e com relevo levemente inclinado com $10 \%$ de declividade e cuja a análise química da camada de 0 a $10 \mathrm{~cm}$ encontra-se na Tabela 1.

TABELA 1. Análise química do solo na camada de 0-10 cm. Londrina-PR, 1996.

\begin{tabular}{|c|c|c|c|c|c|c|c|c|c|}
\hline $\begin{array}{c}\mathrm{pH} \\
\mathrm{CaCl}_{2}\end{array}$ & $\begin{array}{l}\text { M.O. } \\
\text { g/dm }\end{array}$ & $\begin{array}{c}\mathrm{P} \\
\mathrm{mg} / \mathrm{dm}^{3}\end{array}$ & $\mathrm{H}^{+}$ & $\mathrm{Al}^{+3}$ & & $\begin{array}{l}\mathrm{Ca}^{+2} \\
\mathrm{~m}^{3} \\
\end{array}$ & $\mathrm{Mg}^{+2}$ & $(\mathrm{H}+\mathrm{Al})$ & $\begin{array}{l}\mathrm{V} \\
\%\end{array}$ \\
\hline 4,9 & 40,4 & 24,7 & 4,86 & 0,10 & 0,64 & 4,66 & 1,27 & 4,96 & 57 \\
\hline
\end{tabular}

O delineamento experimental adotado foi o de blocos ao acaso com parcelas subdivididas em faixas, com quatro repetições. Os tratamentos principais (parcelas) em número de cinco, foram constituídos pelos herbicidas: testemunha, imazaquin (Scepter) nas doses de 120 e 240 gramas de ingrediente ativo por hectare (g.i.a./ha) aplicado em pré plantio e incorporado e imazethapyr (Pivot) nas doses de 80 e 160 g.i.a./ha aplicado em pré emergência da soja. Os tratamentos secundários (sub-parcelas) em número de seis, foram constituídos pelas épocas de plantio do milho safrinha em sucessão à soja: 0 (zero), 30, 60, 90, 120 e 150 dias após a aplicação dos 
tratamentos. A área total do experimento foi de $4.800 \mathrm{~m}^{2}$, tendo parcelas de $24 \times 10 \mathrm{~m}$ e subparcelas de $4 \times 10 \mathrm{~m}$.

Para a aplicação dos herbicidas, foi utilizado um pulverizador costal pressurizado a $\mathrm{CO} 2$, com pressão constante de $2,8 \mathrm{~kg} / \mathrm{cm}^{2}$, equipado com barra contendo seis bicos do tipo leque da serie Teejet 110.02, distanciados em 50 $\mathrm{cm}$ um do outro, aplicando uma faixa de $3 \mathrm{~m}$ de largura, numa altura de $35 \mathrm{~cm}$ do alvo, com velocidade de trabalho de 1,0 metro por segundo, proporcionando um volume de 200 litros de calda por hectare. O sistema de plantio utilizado foi o convencional, com uma aração e duas gradagens. A aplicação em PPI (imazaquin) foi realizada no dia 11 de novembro de 1995, sendo a incorporação feita imediatamente após a aplicação do produto. A semeadura da soja , cultivar reagente BR-4, foi realizada no dia 13 de novembro do mesmo ano. O espaçamento de plantio foi de $0,45 \mathrm{~m}$ entre linhas e a densidade de 23 sementes por metro linear. Os tratamentos em pré emergência da cultura (imazethapyr) foram aplicados no dia seguinte ao plantio.

A semeadura do milho (Ag 122 - híbrido duplo mais semeado na safrinha) foi realizada nas épocas determinadas (0 (zero), 30, 60, 90, $120 \mathrm{e}$
150 dias após a aplicação - DAA). O primeiro plantio (0 DAA) foi realizado logo após a aplicação dos produtos e para a realizaçaõ dos demais plantios, retirou-se as plantas de soja com o uso de uma roçadeira e preparou-se o solo com uma gradagem leve. $\mathrm{O}$ espaçamento adotado foi de $0,90 \mathrm{~m}$ entre as linhas de plantio, com uma densidade de 6 sementes por metro linear e profundidade de $5,0 \mathrm{~cm}$. A adubação utilizada foi de $330 \mathrm{~kg} / \mathrm{ha}$ da fórmula NPK - 4:20:20. As duas culturas (soja e milho) foram sempre mantidas no limpo (capina manual) e sem a presença de pragas a nível de dano econômico.

As avaliações de fitotoxicidade visual, onde 0 (zero) significou nenhum dano e $100 \%$ morte total das plantas, e a determinação da biomassa seca das plantas de milho (10 pl/parcela) foram realizadas aos 14, 28 (dados não apresentados) e 42 dias após a semeadura (DAS), além da avaliação de produtividade $(\mathrm{kg} / \mathrm{ha})$ no final de cada ciclo. Utilizou-se a irrigação por aspersão sempre que houve déficit hídrico após a semeadura do milho nas diferentes épocas. Os dados meteorológicos durante a condução do experimento encontram-se na Tabela 2.

TABELA 2. Precipitação $(\mathrm{mm})$ e temperatura média $\left({ }^{\circ} \mathrm{C}\right)$ durante a condução do experimento de campo. Londrina-PR (fonte: IAPAR)

\begin{tabular}{cccccccccc}
\hline mês & nov & $\mathbf{d e z}$ & jan & $\mathbf{f e v}$ & mar & abr & mai & jun & jul \\
& $\mathbf{9 5}$ & $\mathbf{9 5}$ & $\mathbf{9 6}$ & $\mathbf{9 6}$ & $\mathbf{9 6}$ & $\mathbf{9 6}$ & $\mathbf{9 6}$ & $\mathbf{9 6}$ & $\mathbf{9 6}$ \\
\hline $\mathbf{( m m})$ & 50,8 & 242,3 & 211,1 & 200,1 & 214,8 & 53,0 & 32,2 & 13,5 & 8,1 \\
$\left({ }^{\circ} \mathbf{C}\right)$ & 23,5 & 24,2 & 24,1 & 23,9 & 23,0 & 21,7 & 18,6 & 16,6 & 16,0 \\
\hline
\end{tabular}

\section{Bioensaio}

Em cada época de semeadura do milho (0, $30,60,90,120$ e 150 DAA) foram coletadas amostras regulares de solo de $0-10 \mathrm{~cm}(3$ pontos por parcela) que após homogeneizadas eram divididas em duas partes: $1 \mathrm{~kg}$ para análise cromatográfica e, aproximadamente, $5 \mathrm{~kg}$ para o bioensaio. Estas amostras foram mantidas congeladas em freezer $\left(-15^{\circ} \mathrm{C}\right)$ até o final do experimento quando foram submetidas a análise e montagem do bioensaio.

O bioensaio foi montado na casa da vegetação da Universidade Estadual de Londrina, adotando-se o mesmo delineamento do ensaio a campo com 4 repetições. Foram utilizados vasos pretos de polietileno com capacidade de $1000 \mathrm{~cm}^{3}$ perfurados no fundo. Para facilitar a drenagem nos vasos, foi colocada uma camada de pedra brita $\mathrm{n}^{\mathrm{o}} 2$, seguida de uma camada de areia grossa, 
completando-se o volume com o solo coletado no experimento de campo. Utilizou-se, como planta teste, o pepino (Cucumis sativus) e as avaliações constaram da medição da altura e peso da biomassa seca das plantas aos 14, 21, 28 (dados não apresentados) e 35 dias após a semeadura, conforme sugere Santelmann (1977).

\section{Análise cromatográfica de resíduos}

As determinações quantitativas de imazaquin e imazethapyr no solo foram feitas por cromatografia de fase líquida (HPLC), utilizandose equipamento "water" do laboratório de Ecofisiologia do IAPAR em Londrina.

\section{Análises estatísticas}

Todos os resultados obtidos no experimento de campo, bioensaio e análises cromatográficas dos resíduos, foram analisados, estatisticamente, através de análises de regressão ao nível de 5\% de probabilidade, segundo Pimentel Gomes (1981). As equações de regressão das variáveis significativas encontram-se na Tabela 3.

\section{RESULTADOS E DISCUSSÃO}

As injúrias mais comumente observadas nas plantas de milho foram a redução de crescimento, nervura central das folhas avermelhadas e cloroses longitudinais no restante das folhas, especialmente nas mais novas. $\mathrm{Na}$ Figura 1 observa-se que, quando o milho foi semeado, logo após a aplicação (0 DAA), o imazaquin na dose normal (120 g.i.a./ha) causou dano quase que total às plantas de milho, enquanto que o imazethapyr não proporcionou fitotoxicidade superior a $30 \%$ na dose normal - 80 g.i.a./ha. A severidade da ação dos herbicidas foi diminuindo, gradativamente, conforme se aumentou o intervalo entre a aplicação dos produtos e a semeadura do milho. Aos 90 DAA a fitotoxicidade observada nos tratamentos com imazethapyr não passava de $10 \%$ e com o imazaquin estes danos não foram superiores a $20 \%$ na dose de 120 g.i.a./ha. Praticamente não se observou nenhuma injúria causada pelos produtos nas dosagens normais aos 120 DAA e aos 150 DAA, nem os tratamentos com as dosagens dobradas prejudicaram o desenvolvimento da cultura.

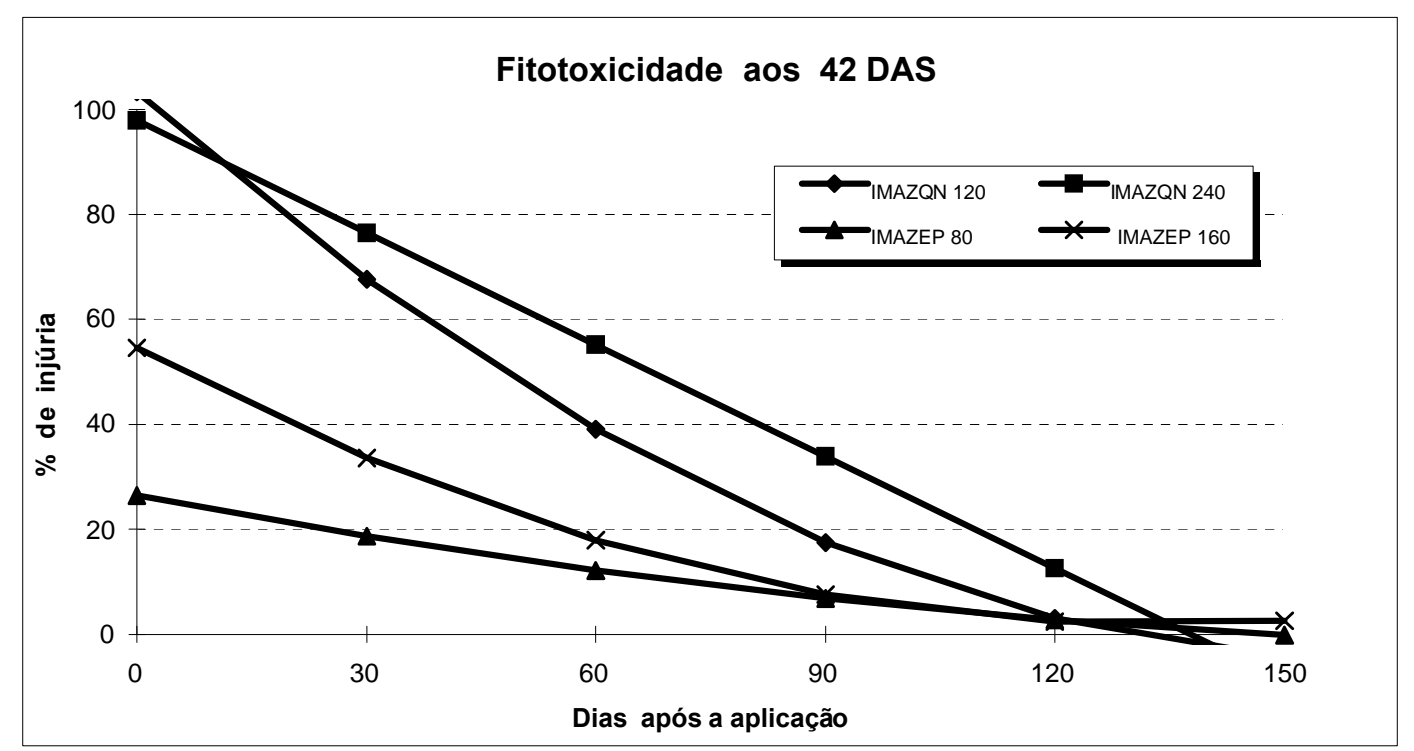

FIGURA 1. Fitotoxicidade visual observada nas plantas de milho aos 42 DAS, em função dos diferentes intervalos entre a aplicação dos herbicidas imazaquin (IMAZQN) e imazethapyr (IMAZEP) e a semeadura do milho. 
TABELA 3. Equações de regressão das variáveis significativas(*).

\begin{tabular}{|c|c|c|c|c|}
\hline & Variável & $\begin{array}{c}\text { Produto/dose } \\
\text { (g.i.a./ha) }\end{array}$ & Equações de regressão & $\mathbf{R}^{2}$ \\
\hline \multirow[t]{4}{*}{ Fig. 1} & Fitotoxicidade aos 42 DAS & IMAZQN 120 & $Y=92,4107-1,0271 X+0,0025 X^{2}$ & 0,97 \\
\hline & & IMAZQN 240 & $Y=98,9732-0,9659 X+0,0019 X^{2}$ & 0,96 \\
\hline & & IMAZEP 80 & $Y=20,4107+0,0286 X-0,0013 X^{2}$ & 0,73 \\
\hline & & IMAZEP 160 & $Y=51,6071-0,5443 X+0,0013 X^{2}$ & 0,97 \\
\hline \multirow[t]{4}{*}{ Fig. 2} & Biomassa de milho aos 42 DAS & IMAZQN 120 & $Y=-1,4485+1,2482 X-0,0037 X^{2}$ & 0,90 \\
\hline & & IMAZQN 240 & $Y=-2,6750+0,7615 X-0,0003 X^{2}$ & 0,94 \\
\hline & & IMAZEP 80 & $Y=82,7790+0,1282 X$ & 0,74 \\
\hline & & IMAZEP 160 & $Y=49,8578+0,3645 X$ & 0,97 \\
\hline \multirow[t]{4}{*}{ Fig. 3} & Produtividade do milho & IMAZQN 120 & $Y=34,6212+0,9977 X-0,0037 X^{2}$ & 0,99 \\
\hline & & IMAZQN 240 & $Y=24,4159+1,1148 X-0,0043 X^{2}$ & 0,99 \\
\hline & & IMAZEP 80 & $Y=76,3763+0,4061 X-0,0016 X^{2}$ & 0,90 \\
\hline & & IMAZEP 160 & $Y=68,1250+0,4321 X-0,0014 X^{2}$ & 0,95 \\
\hline \multirow[t]{4}{*}{ Fig. 4} & Resíduo no solo & IMAZQN 120 & $Y=72,1455-1,2020 X+0,0051 X^{2}$ & 0,87 \\
\hline & & IMAZQN 240 & $Y=52,6045-0,7776 X+0,0031 X^{2}$ & 0,92 \\
\hline & & IMAZEP 80 & $Y=148,1690-2,1466 X+0,0080 X^{2}$ & 0,99 \\
\hline & & IMAZEP 160 & $Y=92,1375-1,2579 X+0,0046 X^{2}$ & 0,99 \\
\hline \multirow[t]{4}{*}{ Fig. 5} & Biomassa do pepino aos 35 DAS & IMAZQN 120 & $Y=14,9583+0,7976 X-0,0010 X^{2}$ & 0,97 \\
\hline & & IMAZQN 240 & $Y=11,1629+0,5986 X+0,0005 X^{2}$ & 0,97 \\
\hline & & IMAZEP 80 & $Y=21,2903+0,9320 X-0,0026 X^{2}$ & 0,94 \\
\hline & & IMAZEP 160 & $Y=16,0280+0,9991 X-0,0027 X^{2}$ & 0,96 \\
\hline
\end{tabular}

(*) IMAZQN - Imazaquin ; IMAZEP - Imazethapyr. 
Houve uma correlação bastante estreita entre as avaliações de fitotoxicidade visual e a determinação da biomassa seca das plantas de milho. Na Figura 2 pode-se observar que a biomassa seca do milho é bem mais afetada pelo imazaquin do que pelo imazethapyr. Inicialmente (0 DAA) os danos dos produtos foram acentuados e aos 120 DAA não houve grandes diferenças em relação à testemunha. Resultados semelhantes foram encontrados por Renner et al. (1988).

Com relação à produtividade do milho obtida após os diferentes tratamentos, a Figura 3 confirma as observações anteriores de fitotoxicidade e biomassa seca, mostrando que a produtividade da cultura também é mais afetada pelo imazaquin do que pelo imazethapyr. Aos 0 (zero) DAA o imazethapyr na dose de 80 g.i.a./ha reduziu em $24 \%$ a produtividade do milho, enquanto que o imazaquin a 120 g.i.a./ha diminuiu este mesmo parâmetro em 66\%. De todas as determinações feitas neste experimento, a de maior interesse direto do agricultor é se existe algum risco de perda na produtividade, ou ainda, quantos dias após a aplicação destes produtos na soja poderia se plantar o milho sem que ocorresse diminuição na produtividade. Tomando-se por base as equações encontradas, determinou-se que neste caso específico, após 90 dias da aplicação de imazethapyr (80 g.i.a./ha) e 112 dias após a aplicação de imazaquin (120 g.i.a./ha) não houve nenhuma diferença de produtividade do milho entre as áreas tratadas ou não com estes herbicidas. Nas dosagens dobradas os intervalos encontrados foram um pouco maiores, sendo 122 dias para imazethapyr (160 g.i.a./ha) e 133 dias para imazaquin ( 240 g.i.a./ha).

Os resultados das análises cromatográficas de resíduos estão apresentados na Figura 4. A recuperação dos produtos em solo "fortificado" foi de $80 \%$ para o imazaquin e de $83 \%$ para o imazethapyr. Observou-se que a degradação do imazaquin é bem mais acentuada que a do imazethapyr, apesar de todos os dados anteriores revelarem uma ação mais danosa ao milho daquele herbicida em relação a este. Renner et al. (1988) encontrou esta mesma situação de maior quantidade de imazethapyr em relação ao imazaquin, apesar de observar maiores injúrias com o imazaquin. Loux \& Reese (1993) e Stougaard et al. (1990) citam que a maior tolerância do milho ao imazethapyr em relação ao imazaquin não é devido à persistência e sim pela diferença de adsorção entre os dois produtos; eles sugerem uma adsorção mais intensa do imazethapyr ao solo, ficando menos disponível para as plantas. Polge \& Barrett (1997) citam que, apesar de ser muito importante a análise química quantitativa dos resíduos no solo, esta não define o risco de injúrias destes produtos às culturas subsequentes, sendo também necessário o bioensaio com plantas sensíveis.

$\mathrm{O}$ bioensaio confirmou a alta sensibilidade das plantas de pepino a estes produtos conforme Onofri (1996). Não foram observadas grandes diferenças entre as injúrias causadas pelo imazaquin e pelo imazethapyr. Os dois produtos causaram redução de crescimento, com clorose acentuada nas folhas mais novas. Na Figura 5 pode-se observar que as curvas estão muito próximas umas das outras e tendo por base as equações de cada tratamento, os intervalos encontrados para a degradação dos produtos, foram maiores do que aqueles encontrados para o milho. As curvas de biomassa seca das plantas de pepino mostram intervalos de 127 e 135 DAA para o imazethapyr (80 g.i.a./ha) e para o imazaquin (120 g.i.a./ha) respectivamente, não havendo mais interferência destes herbicidas após estes intervalos. 


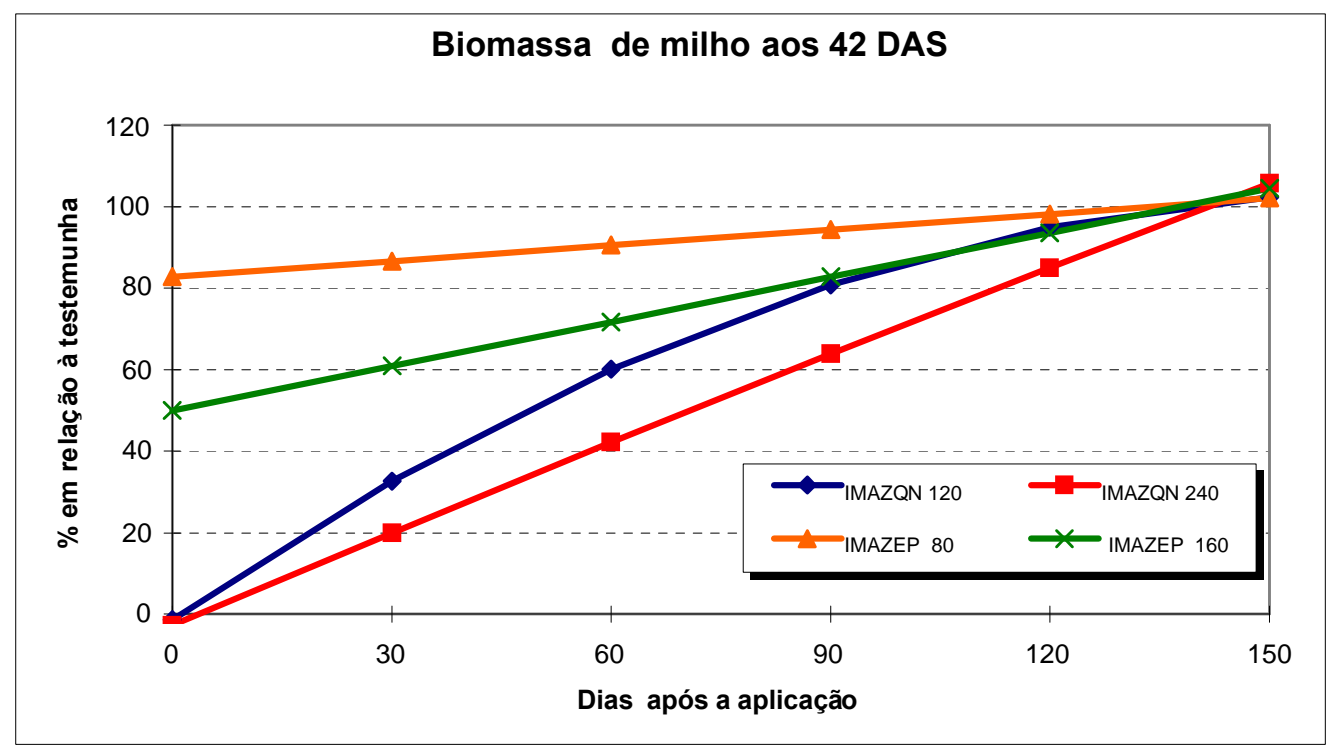

FIGURA 2. Biomassa seca das plantas de milho (\% em relação à testemunha) aos 42 DAS, em função dos diferentes intervalos entre a sua semeadura e a aplicação dos herbicidas imazaquin e imazethapyr.

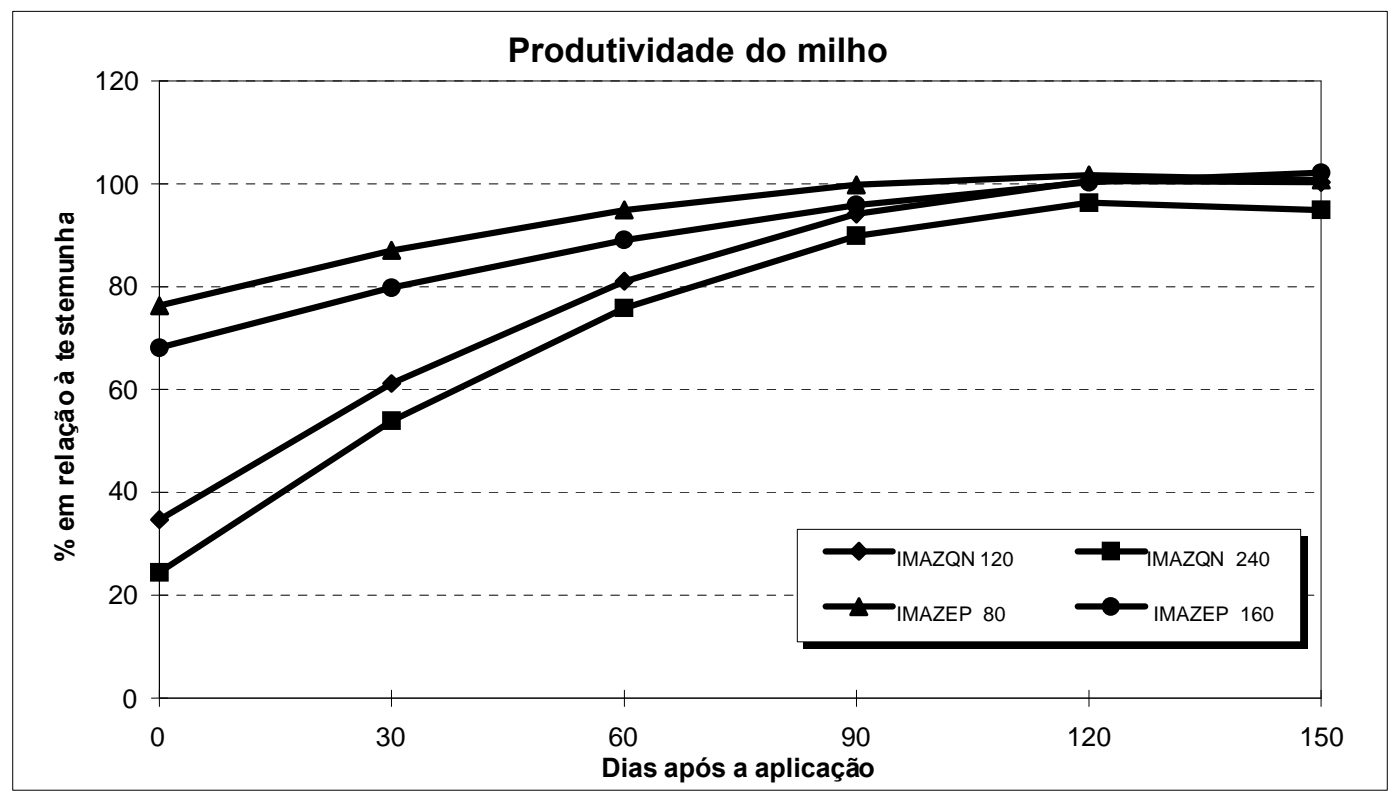

FIGURA 3. Produtividade da cultura do milho (\% em relação à testemunha), em função dos diferentes intervalos entre a sua semeadura e a aplicação dos herbicidas imazaquin e imazethapyr. 


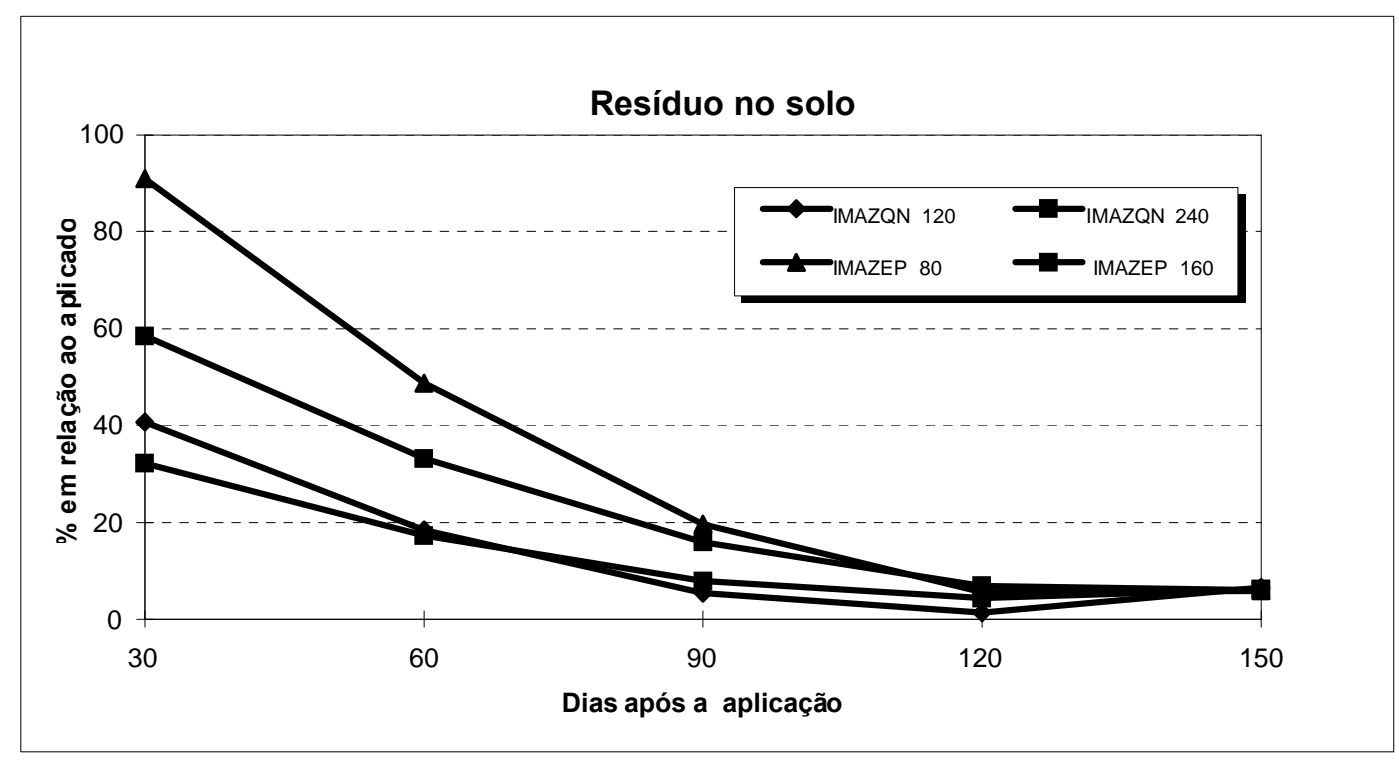

FIGURA 4. Resíduo dos produtos no solo (\% em relação ao aplicado - 0 DAA), em função dos diferentes intervalos entre a aplicação dos herbicidas e a semeadura do milho .

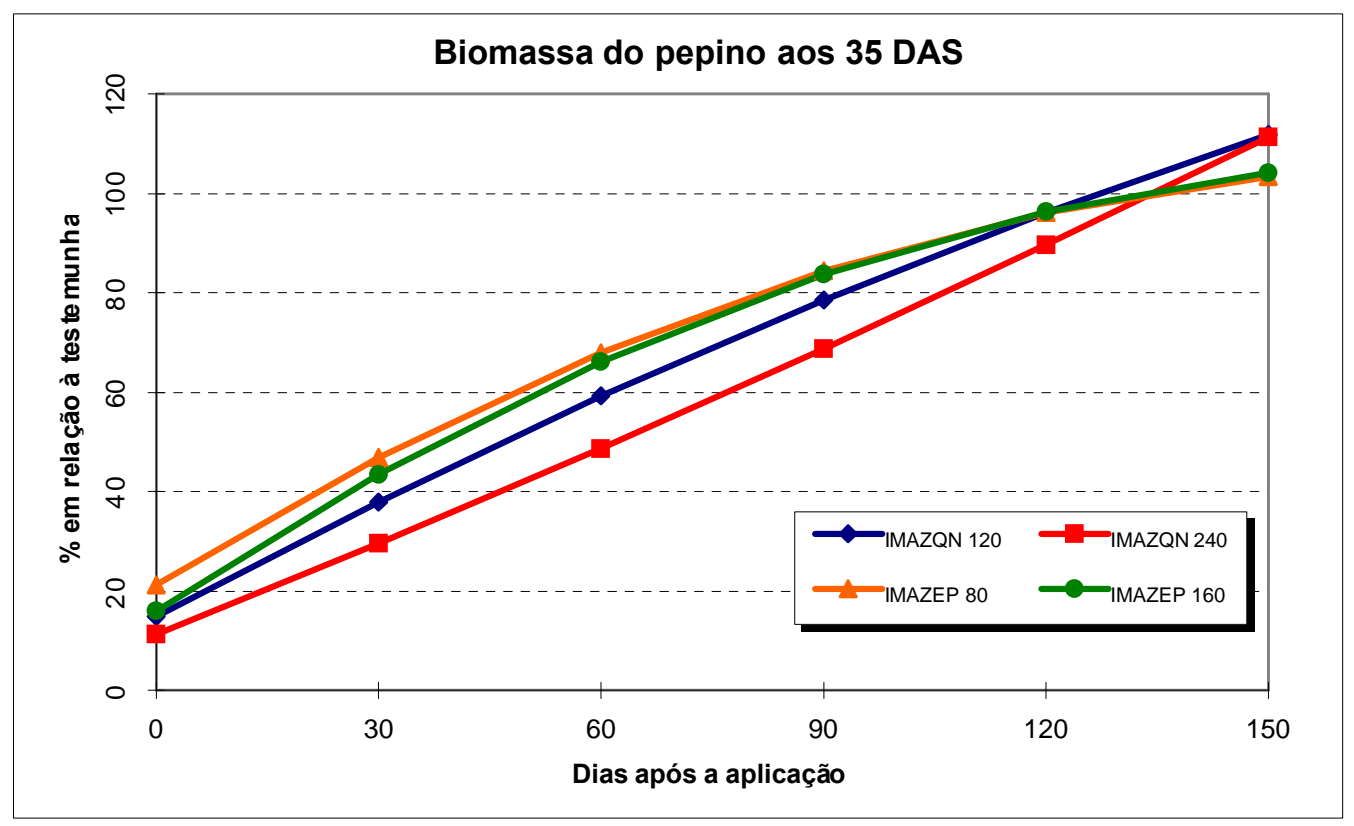

FIGURA 5. Biomassa seca das plantas de pepino (\% em relação à testemunha) aos 35 DAS, em função dos diferentes intervalos após a aplicação dos herbicidas imazaquin e imazethapyr no campo. 
Correlacionando os parâmetros avaliados, nota-se que mesmo não interferindo na produtividade do milho, os intervalos encontrados de 90 e 112 dias, para imazethapyr e imazaquin respectivamente, ainda causaram sintomas de fitotoxicidade inicial, com valores de $8 \%$ para imazaquin e $12 \%$ para imazethapyr. No caso do pepino estes valores são ainda maiores: $9 \%$ para imazaquin e $16 \%$ para imazethapyr nos mesmos intervalos. Portanto, mesmo mostrando sintomas de injúria no início do desenvolvimento, as plantas de milho se recuperaram, tendo produtividade normal após estes intervalos. Resultados semelhantes a esses, foram encontrados por Mills \& Witt (1989) que observaram sintomas de fitotoxicidade no milho, sem afetar a sua produtividade.

\section{LITERATURA CITADA}

BASHAN, G.W., LAVY, I.L. Microbial and photolic dissipation of imazaquin in soil. Weed Sci., v. 35, p. 865-870, 1987.

CANTWELL, J.R., LIEBL, R.A., SLIFE, F.W. Biodegradation characteristics of imazaquin and imazethapyr. Weed Sci., v. 37, p. 815819, 1989.

CURRAN, W.S., KNAKE, E.L., LIEBL, R.A. Corn (Zea mays) injury following use of clomazone, chlorimuron, imazaquin, and imazethapyr. Weed Technol., v. 5, p. 539$544,1991$.

CURRAN, W.S., LIEBL, R.A., SIMMONS, F.W. Effects of tillage and application method on clomazone, imazaquin, and imazethapyr persistence. Weed Sci., v. 40, p. 482-489, 1992.

FLINT, J.L., WITT, W.W. Microbial degradation of imazaquin and imazethapyr. Weed Sci., v. 45, p. 586-591, 1997.

GOETZ, A.J., WEHTJE, G., WALKER, R.H., HAJEK, B. Soil solution and mobility characterization of imazaquin. Weed Sci., v. 34, p. 788-793, 1986.

IBGE - INSTITUTO BRASILEIRO DE GEOGRAFIA E ESTATÍSTICA. Anu.

Estat. Brasil, v. 56, p. 551, 1996.

JOHNSON, D.H., TALBERT, R.E. Cotton (Gossypium hirsutum) response to imazaquin and imazethapyr soil residues. Weed Sci., v. 44, p. 156-161, 1996.

LOUX, M.M., LIEBL, R.A., SLIFE, F.W. Availability and persistence of imazaquin, imazethapyr, and clomazone in soil. Weed Sci., v. 37, p. 259-267, 1989.

LOUX, M.M., REESE, K.D. Effects of soil pH on adsoption and persistence of imazaquin.

Weed Sci., v. 40, p. 490-496, 1992.

LOUX, M.M., REESE, K.D. Effect of soil type and $\mathrm{pH}$ on pesistence and carryover of imidazolinone herbicides. Weed Technol., v. 7, p. 452-458, 1993.

MARSH, B.H., LLOYD, R.W. Soil pH effect on imazaquin persistence in soil. Weed Technol, v. 10, p. 337-340, 1996.

MILANOVA, S., GRIGOROV, P. Movement and persistence of imazaquin, oxyfluorfen, flurochloridone and terbacil in soil. Weed Res., v. 36, p. 31-36, 1996.

MILLS, J.A., WITT, W.W. Efficacy, phytotoxicity, and persistence of imazaquin, imazethapyr, and clomazone in no-till double-crop soybeans (Glycine max). Weed Sci., v. 37, p. 353-359, 1989.

MOYER, J.R., ESAU, R. Imidazolinone herbicide effects on following rotational crops in Southern Alberta. Weed Technol., v. 10, p. 100-106, 1996. 
ONOFRI, A. Biological activity, field persistence and safe recropping intervals for imazethapyr and rimsulfuron on a silty-clay soil. Weed Res., v. 36, p. 73-83, 1996.

PIMENTEL GOMES, F. Curso de estatística experimental. 9ed. Piracicaba: Nobel, 1981. 430p.

POLGE, N.D., BARRETT, M. Temperature effects on imazaquin soil bioavailability, uptake, and metabolism in corn (Zea mays). Weed Sci., v. 45, p. 198-204, 1997.

RENNER, K.A., MEGGITT, W.F., PENNER, D. Effect of soil $\mathrm{pH}$ on imazaquin and imazethapyr adsorption to soil and phytotoxicity to corn (Zea mays). Weed Sci., v. 36, p. 78-83, 1988.
RODRIGUES, B.N., ALMEIDA, F.S. Guia de Herbicidas. 3.ed. Londrina: Ed. Autores, 1995. 675p.

SANTELMANN, P.W. Herbicide bioassay. In: Southern Weed Science society. Research Methods in Weed Science, 2 ed. Auburn: Truelove, B., 1977. p. 79-87.

SHANER, D.L., ANDERSON, P.C., STIDHAM, M.A. Imidazolinones, potent inhibitors of acetohydroxyacid synthase. Plant Physiol., v. 75, p. 545-546, 1984.

STOUGAARD, R.N., SHEA, P.J., MARTIN, A.R. Effects of soil type and $\mathrm{pH}$ on adsorption, mobility, and efficacy of imazaquin and imazethapyr. Weed Sci., v. 38, p. 67-73, 1990. 